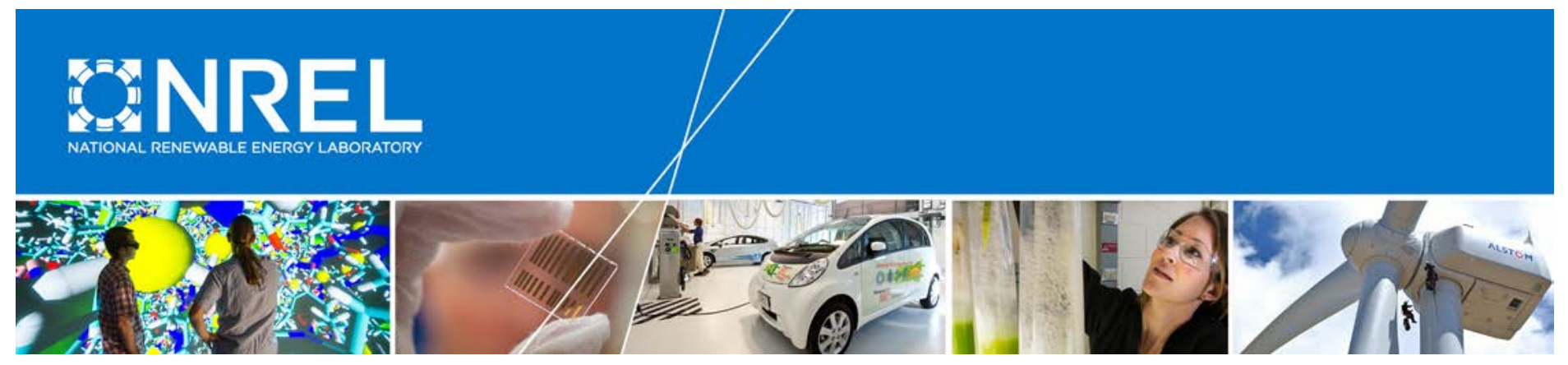

\title{
Predicting Cavitation on Marine and Hydrokinetic Turbine Blades with AeroDyn V15.04
}

Robynne Murray

National Renewable Energy Laboratory

NREL is a national laboratory of the U.S. Department of Energy Office of Energy Efficiency \& Renewable Energy Operated by the Alliance for Sustainable Energy, LLC

This report is available at no cost from the National Renewable Energy Laboratory (NREL) at www.nrel.gov/publications.

Technical Report

NREL/TP-5000-68398

August 2017

Contract No. DE-AC36-08G028308 


\section{Predicting Cavitation on Marine and Hydrokinetic Turbine Blades with AeroDyn V15.04}

Robynne Murray

National Renewable Energy Laboratory

Prepared under Task No(s). WAPP.10343.10.01.01
National Renewable Energy Laboratory 15013 Denver West Parkway Golden, CO 80401

303-275-3000 • www.nrel.gov
NREL is a national laboratory of the U.S. Department of Energy Office of Energy Efficiency \& Renewable Energy Operated by the Alliance for Sustainable Energy, LLC

This report is available at no cost from the National Renewable Energy Laboratory (NREL) at www.nrel.gov/publications.

\section{Technical Report}

NREL/TP-5000-68398

August 2017

Contract No. DE-AC36-08GO28308 


\section{NOTICE}

This report was prepared as an account of work sponsored by an agency of the United States government. Neither the United States government nor any agency thereof, nor any of their employees, makes any warranty, express or implied, or assumes any legal liability or responsibility for the accuracy, completeness, or usefulness of any information, apparatus, product, or process disclosed, or represents that its use would not infringe privately owned rights. Reference herein to any specific commercial product, process, or service by trade name, trademark, manufacturer, or otherwise does not necessarily constitute or imply its endorsement, recommendation, or favoring by the United States government or any agency thereof. The views and opinions of authors expressed herein do not necessarily state or reflect those of the United States government or any agency thereof.

This report is available at no cost from the National Renewable Energy Laboratory (NREL) at www.nrel.gov/publications.

Available electronically at SciTech Connect http:/www.osti.gov/scitech

Available for a processing fee to U.S. Department of Energy and its contractors, in paper, from:

U.S. Department of Energy

Office of Scientific and Technical Information

P.O. Box 62

Oak Ridge, TN 37831-0062

OSTI http://www.osti.gov

Phone: 865.576.8401

Fax: 865.576.5728

Email: reports@osti.gov

Available for sale to the public, in paper, from:

U.S. Department of Commerce

National Technical Information Service

5301 Shawnee Road

Alexandria, VA 22312

NTIS http://www.ntis.gov

Phone: 800.553 .6847 or 703.605 .6000

Fax: 703.605.6900

Email: orders@ntis.gov 


\section{Acknowledgments}

This work was supported by the U.S. Department of Energy under Contract No. DE-AC3608GO28308 with the National Renewable Energy Laboratory. Funding for the work was provided by the DOE Office of Energy Efficiency and Renewable Energy, Water Power Technologies Office.

The authors would also like to thank Michael Togneri for providing airfoil data for the NREL S814 airfoils tested at Strathclyde University, and AbuBakr Bahaj for data for the 800-mm turbine tested at Southampton University. 


\section{Nomenclature or List of Acronyms}

BEM

MHK

NREL

TSR

$a$

$a^{\prime}$

$C_{P \text { min }}$

$\mathrm{C}_{\mathrm{P}}$

$\mathrm{C}_{\mathrm{T}}$

$g$

$h$

$\sigma$

$\sigma_{\text {crit }}$

$\rho$

$P_{\text {atm }}$

$P_{L}$

$P_{\text {vap }}$

$r$

$U_{\infty}$

$V_{\text {rel }}$

$\omega$ blade element momentum

marine and hydrokinetic

National Renewable Energy Laboratory

tip-speed ratio

axial induction factor (-)

tangential induction factor (-)

minimum pressure coefficient (-)

power coefficient (-)

thrust coefficient (-)

gravitational constant $\left(\mathrm{m} / \mathrm{s}^{2}\right)$

submerged depth (m)

cavitation number (-)

critical cavitation number (-)

density of fluid $\left(\mathrm{kg} / \mathrm{m}^{3}\right)$

atmospheric pressure $(\mathrm{Pa})$

local pressure $(\mathrm{Pa})$

vapor pressure $(\mathrm{Pa})$

radius $(\mathrm{m})$

undisturbed inflow velocity $(\mathrm{m} / \mathrm{s})$

relative velocity $(\mathrm{m} / \mathrm{s})$

rotational velocity $(\mathrm{rad} / \mathrm{s})$ 


\section{Table of Contents}

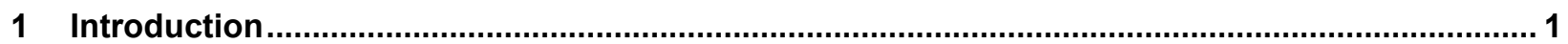

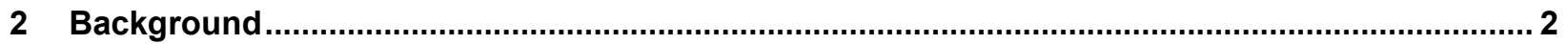

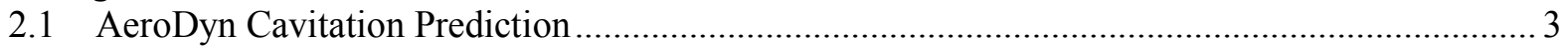

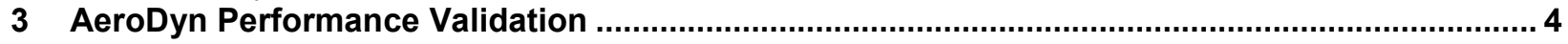

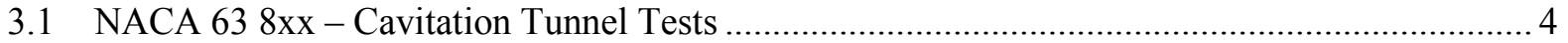

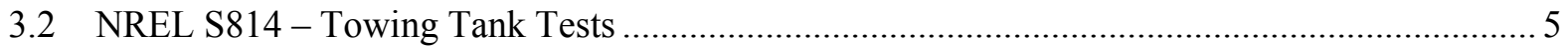

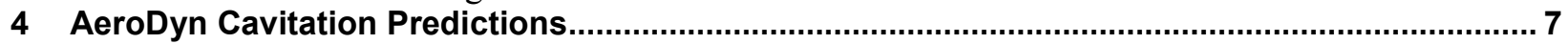

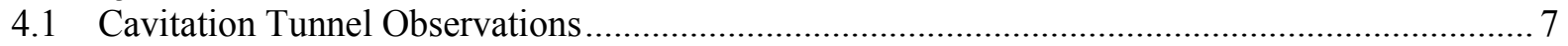

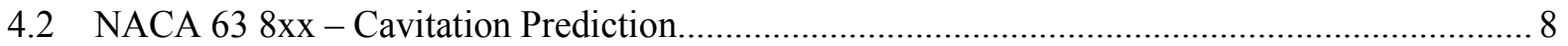



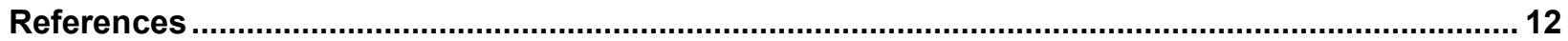

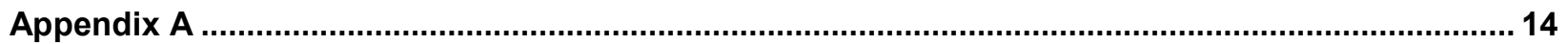

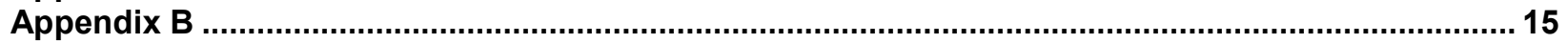



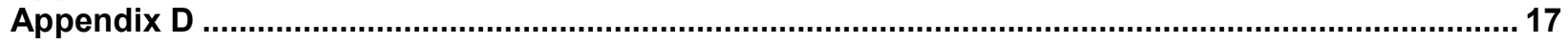

\section{List of Figures}

Figure 1. $C_{p}$-TSR AeroDyn compared to experimental tests done by Bahaj et al. (Bahaj et al. 2007) for an 800-mm-diameter turbine.

Figure 2. $C_{p}$ and $C_{T}$ versus TSR, AeroDyn compared to experimental tests conducted by Doman et al. (Doman et al. 2015) for a 782-mm-diameter turbine .................................................................. 6

Figure 3. Critical cavitation numbers (markers) and local cavitation numbers (lines) for the 800 -

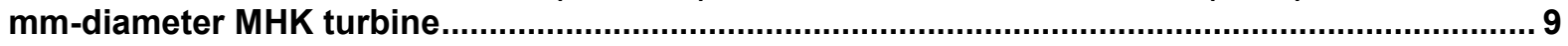

Figure 4. Ratio of local cavitation number to critical cavitation number for the 800 -mm-diameter

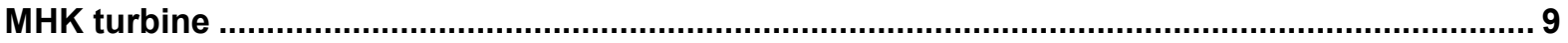

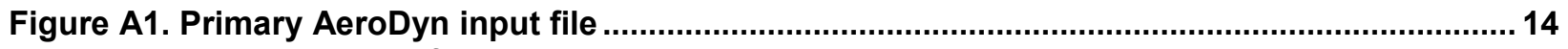



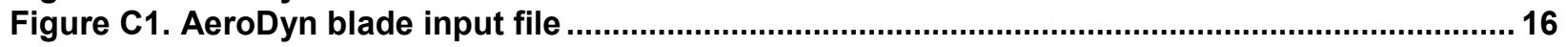



\section{List of Tables}

Table 1. Cavitation Prediction of AeroDyn Compared to Experimental Observations ....................... 7 


\section{Introduction}

As the marine and hydrokinetic (MHK) industry moves toward design and deployment of fullscale devices, reliable development tools are going to play a crucial role in the success of this effort. Currently, uncertainty in the design process leads to high safety factors that necessitate heavy, overdesigned, and expensive structures. Current estimates state that manufacturing and deployment make up 53.3\% of the cost of energy, and operations and maintenance make up 30\% of the total levelized cost of energy of a horizontal-axis tidal turbine (Neary et al. 2014). Therefore, appropriate device design using reliable and verified design tools is essential to limiting turbine failures and expensive downtime while developing cost-effective devices.

A range of design tools with different levels of model fidelity are used in the MHK industry depending on the stage of development. For early-stage design and prediction of MHK turbine performance and loads, blade element momentum (BEM) theory is often used because of its simplicity and computational efficiency. BEM theory is an analytical model that iterates between momentum theory and blade element theory, as originally published by Glauert (Glauert 1935). In this method, the blade is discretized into elements along the length and 2D aerodynamic forces and moments are calculated at nodes (one node per element at the aerodynamic center, $1 / 4$ chord) as distributed loads per unit length. These 2D distributed loads are integrated over the blade length to approximate 3D aerodynamic loads over the entire blade. This modeling approach has been applied to wind turbines (Burton et al. 2001), and plays a major role in technology development in the tidal energy industry (Galloway, Myers, and Bahaj 2011, Clarke et al. 2007, Nevalainen, Johnstone, and Grant 2015, Gracie et al. 2015, Murray et al. 2016). These models are fast and efficient, facilitating a large number of design trials prior to the use of higher-cost computational tools. The concept behind BEM theory and its application to turbine modeling can be found in (Hansen 2008).

The objective of this work is to validate an open-source performance tool that can be used to predict tidal turbine performance, as well as cavitation inception on MHK blades. To achieve this objective, the National Renewable Energy Laboratory's (NREL's) engineering tool AeroDyn (Jonkman et al. 2016) was updated to version 15.04 to enable users to predict the likelihood of cavitation inception at locations along the blade span. AeroDyn is a time-domain wind turbine aerodynamics module that uses BEM theory to compute the loads on turbines based on user defined sectional lift and drag data, and input operating conditions. More detail on the cavitation implementation in AeroDyn is given in Section 2. This report validates the updated AeroDyn program for MHK turbines using two publicly available data sets. It also presents a verification of the AeroDyn prediction of cavitation inception on MHK blades based on experimental observations. 


\section{Background}

The design of an MHK rotor is governed by hydrodynamic performance and structural requirements, and in the case of MHK turbines, the blade airfoils have to be designed to limit and delay cavitation inception. As the velocity of the fluid increases over the turbine airfoil, the hydrodynamic pressure decreases according to Bernoulli's principle. Cavitation occurs when the hydrostatic pressure on the blade surface drops to or below the vapor pressure of the fluid. This pressure drop results in the formation of bubbles that implode on the blade surface, causing cyclic surface fatigue. This pitting of the blade surface not only deteriorates the airfoil performance, but can affect it over the long term (Buckland et al. 2013, Barber and Motley 2016). Because of the cost and complexity of maintaining MHK devices that are installed in extreme subsea environments, cavitation damage to the blades is costly to repair. Thus, cavitation should be avoided when designing MHK rotors.

Cavitation inception can be predicted by the nondimensional cavitation number, $\sigma_{\text {crit }}$, which depends on the local relative velocity of the blade, $V_{\text {rel }}$, the undisturbed free-stream pressure, the density, $\rho$, and the vapor pressure of the fluid, $P_{\text {vap }}$ (typically around 2,000 Pa for seawater). $P_{\text {atm }}$ is the atmospheric pressure above the free surface, $h$ is the submerged depth (distance to the free surface), and the undisturbed free-stream pressure is the sum of the surface pressure, $P_{\text {atm }}$, and the gravitational pressure of the fluid acting on the blade, $\rho g h$. The critical cavitation number is the number above which cavitation will occur, and is given by:

$$
\sigma_{\text {crit }}=\frac{\left(P_{\text {atm }}+\rho g h\right)-P_{\text {vap }}}{\frac{1}{2} \rho V_{\text {rel }}^{2}}
$$

$V_{\text {rel }}$ is the relative velocity on the blade section based on the local radial positon of the node, $r$, the undisturbed free-stream velocity, $U_{\infty}$, the rotational velocity, $\omega$ (in radians/second), and the axial, $a$, and tangential, $a^{\prime}$, induction factors:

$$
V_{\text {rel }}=\sqrt{U_{\infty}(1-a)^{2}+r^{2} \omega^{2}\left(1+a^{\prime}\right)^{2}}
$$

It should be noted that the relative velocity given in Eq. 2 is a simplification of the expression implemented within AeroDyn, which also includes the effects of inflow variations (shear, tilt/yaw error, turbulence, and structural vibrations). Cavitation occurs when the local cavitation number is greater than or equal to the critical cavitation number (cavitation occurs when $\sigma_{\text {crit }}<\sigma$ ), which is based on the minimum pressure coefficient of the blade section and is given by:

$$
\sigma=\frac{\left(P_{\mathrm{atm}}+\rho g h\right)-P_{L}}{\frac{1}{2} \rho V_{\mathrm{rel}}^{2}}=-C_{P \text { min }}
$$


The local pressure on the airfoil surface, $P_{L}$, is not often known in practice due to difficulties measuring blade pressures experimentally, hence the nondimensional minimum surface pressure coefficient, $C_{P \min }$, is used. $C_{P \min }$ varies as a function of the angle of attack for a particular airfoil section, similarly to the lift and drag coefficients. The panel method, XFOIL (Drela 2001), is commonly used to estimate minimum pressure coefficients for MHK blade profiles (Molland et al. 2004, Batten et al. 2008, Buckland et al. 2013).

\subsection{AeroDyn Cavitation Prediction}

AeroDyn is an open-source BEM theory performance tool that is supported and maintained by NREL (Jonkman et al. 2016). It can also be coupled to NREL's FAST (Jason M. Jonkman 2005) platform for full-turbine fluid-structure interaction design. In the latest version of Aerodyn V15.04, a cavitation check flag was included which the user can turn on or off. Therefore, additional options were added to the AeroDyn input file to allow the user to specify the atmospheric pressure, fluid vapor pressure, and the submerged hub depth, which are required to perform a cavitation check.

In AeroDyn V15.04, the critical and local cavitation numbers are calculated for each blade node along the span. During each blade rotation, the distance from the blade node in question to the free surface varies; the closer the blade node is to the free surface, the more likely cavitation will occur. The distance from the free surface to the blade node is calculated using the nodal position (z-coordinate of the node in the global coordinate system given in (Jason M. Jonkman 2005)), which includes the blade displacement, relative to the center of the hub.

In AeroDyn V15, the blade airfoil aerodynamics can be steady or unsteady. In the steady model, the static airfoil lift, drag, and pitching-moment coefficient data, together with the angle of attack computed using BEM theory, is used to calculate nodal loads. The unsteady model accounts for flow hysteresis, including unsteady attached flow, trailing-edge flow separation, dynamic stall, and flow reattachment. When a cavitation check is flagged by the user, the program requires that the airfoil aerodynamics are steady and the minimum pressure coefficient $C_{P \min }$ is calculated along with the other airfoil coefficient data. AeroDyn V15.04 sample files and documentation can be found at the NWTC Portal (Hayman, Jonkman, and Murray 2017). 


\section{AeroDyn Performance Validation}

To validate that the updated AeroDyn V15.04 design tool works adequately for predicting the performance of MHK turbines, it was compared against two sets of MHK experimental data provided in (Bahaj et al. 2007) and (Doman et al. 2015).

For both turbines modeled in AeroDyn, Prandtl's tip and hub-loss model, as well as the tangential induction factor, were used in the BEM theory calculations. Prandtl's tip and hub-loss correction factors are used to account for losses in efficiency and power production due to spanwise flow and vortex shedding at the blade tip and hub. In addition, aerodynamic drag was used in the calculation of both the axial and tangential-induction calculations (an optional flag in the AeroDyn input file).

\subsection{NACA 63 8xx - Cavitation Tunnel Tests}

The AeroDyn turbine performance predictions were compared to experimental data produced by Bahaj et al. (Bahaj et al. 2007) for an 800-mm-diameter turbine tested in a cavitation tunnel. The flow speed was fixed at $1.73 \mathrm{~m} / \mathrm{s}$ and the rotational speeds were varied to cover a range of tipspeed ratios (TSRs). The turbine and blade geometry can be found in (Bahaj et al. 2007). Airfoil data for the NACA 63 8xx airfoil used in AeroDyn was obtained using XFOIL (Drela 2001) at the appropriate Reynolds numbers, as was done by Bahaj et al. in (Bahaj, Batten, and McCann 2007), and the blades were modeled with 17 blade nodes. Note that the lift and drag airfoil data was corrected for rotational augmentation using NREL's AirfoilPrep tool (Ning 2013), however, the $C_{P \min }$ data used in Section 4 was not corrected or adjusted. The input files to model this turbine in AeroDyn are given in the Appendices A through D. Figure 1 shows the power and thrust coefficients, $\mathrm{C}_{\mathrm{P}}$ and $\mathrm{C}_{\mathrm{T}}$, for both the experiment and the AeroDyn program. 




Figure 1. $C_{p}-$ TSR AeroDyn compared to experimental tests done by Bahaj et al. (Bahaj et al. 2007) for an 800 -mm-diameter turbine

Figure 1 shows that AeroDyn predicts the power coefficient well, but underpredicts the thrust coefficients by approximately $5 \%$. However, this comparison does not consider uncertainty or scatter in the experiment, and the fit to the performance prediction is equivalent to other validations performed in the industry.

\subsection{NREL S814 - Towing Tank Tests}

The second data set used for AeroDyn V15.04 validation was from towing tank tests presented in Doman et al. (Doman et al. 2015). A three-bladed, 782-mm-diameter turbine with NREL S814 airfoil-shaped blades was tested in the University of Strathclyde towing tank at a flow speed of 1 $\mathrm{m} / \mathrm{s}$ and varying rotational speeds. More information on the turbine geometry and tests can be found in (Doman et al. 2015). The NREL S814 airfoil lift and drag data used in AeroDyn was based on tests performed by Togneri et al. (Togneri et al. 2015) in a flume with a Reynolds number of $5 \times 10^{4}$. Twenty blade nodes were used. Figure 2 shows the power and thrust coefficients for both the experiment and the AeroDyn program. 




Figure 2. $C_{p}$ and $C_{T}$ versus TSR, AeroDyn compared to experimental tests conducted by Doman et al. (Doman et al. 2015) for a 782-mm-diameter turbine

In general, AeroDyn performs acceptably for a TSR greater than 3.25; however, for a TSR of less than 3.25, AeroDyn significantly overpredicts the power coefficient. This overprediction is thought to be a result of the increasingly low Reynolds number in the tests at a low TSR that was not modeled through changes to the airfoil data. Previous work shows that the performance of the NREL S814 airfoil varies significantly with Reynolds number in this low range (Milne 2014). Because the airfoil data used in the design tool was for a single Reynolds number, it did not capture the effect of varying Reynolds number on the performance of the turbine.

Sources of error between the AeroDyn program and the experimental results include blockage effects that may have been present in the towing tank and cavitation tunnel tests (AeroDyn does not account for these), and limitations in predicting or experimentally obtaining airfoil data at the low Reynolds numbers tested. Selecting appropriate airfoil data (lift, drag and minimum pressure coefficients) is one of the most critical components to predicting turbine performance and cavitation using BEM theory tools such as AeroDyn. For both the NACA 63 8xx and NREL S814 experimental data sets, the match achieved was comparable to similar validations done by other researchers in the industry (Batten et al. 2007, Germain et al. 2007, Murray 2016) and was considered acceptable. 


\section{AeroDyn Cavitation Predictions}

\subsection{Cavitation Tunnel Observations}

Bahaj et al. (Bahaj et al. 2007) tested an 800-mm-diameter MHK turbine (the same turbine as presented in Section 3.1) in the cavitation tunnel at Haslar Marine Technology Park, Gosport, United Kingdom under various pressure and operating conditions. The cavitation tunnel at Haslar Marine Technology Park is $5 \mathrm{~m}$ long by $2.4 \mathrm{~m}$ wide and $1.2 \mathrm{~m}$ deep, with an adjustable pressure ranging from $0.2-1.2 \mathrm{~atm}$. The flow speed during the tests was fixed, and the working section static pressure in the tunnel was decreased as required until cavitation was observed using a light and a video recording system. This turbine was modeled using AeroDyn V15.04 and compared to the experimental observations.

The AeroDyn turbine model was set up similarly to Section 3.1 (e.g., 17 nodes, XFOIL airfoil lift and drag data). The minimum pressure coefficient data for the NACA 63 8xx airfoil was obtained by Buckland et al. (Buckland et al. 2013) using XFOIL for angles of attack from $0^{\circ}$ to $15^{\circ}$ and then extrapolated for the full $-180^{\circ}$ to $180^{\circ}$ range. A midhub depth of $0.6 \mathrm{~m}$ from the free surface was assumed based on the cavitation tunnel dimensions. To simulate the cavitation tunnel conditions, the atmospheric pressure was adjusted in the AeroDyn input file to achieve the same critical cavitation number for the blade tip as given in (Bahaj et al. 2007). The percentage of the blade predicted to cavitate by the model was then compared to that observed in the experiment. In this case, for comparison to the experiment, the cavitation number was calculated with the blade in the top- dead-center position, giving the most conservative estimate of cavitation inception.

For a tunnel flow speed of $1.4 \mathrm{~m} / \mathrm{s}$, a root pitch setting of $25^{\circ}$, a static pressure of $21,000 \mathrm{~Pa}$, a TSR of 7.2, and $\sigma_{\text {crit }}$ of 0.64, Bahaj et al. (Bahaj et al. 2007) observed cavitation over approximately $15 \%$ of the blade. With the same cavitation number, the AeroDyn model predicted cavitation to occur on $18 \%$ to $24 \%$ of the blade. Other cavitation tunnel test conditions are compared in Table 1.

Table 1. Cavitation Prediction of AeroDyn Compared to Experimental Observations

\begin{tabular}{|l|l|l|l|l|l|l|}
\hline \multicolumn{3}{|c|}{ Bahaj Experiment } & \multicolumn{1}{|c|}{ AeroDyn Model } \\
\hline TSR & $\begin{array}{c}\text { Static pressure } \\
\text { exp. (Pa) }\end{array}$ & $\begin{array}{c}\boldsymbol{\sigma}_{\text {crit }} \\
\text { exp. }\end{array}$ & $\begin{array}{c}\text { Percent } \\
\text { cavitation observed } \\
(\%)\end{array}$ & $\begin{array}{c}\mathbf{P}_{\text {atm }} \text { input } \\
(\mathbf{P a})\end{array}$ & $\begin{array}{c}\text { Percent } \\
\boldsymbol{\sigma}_{\text {crit }} \\
\text { model }\end{array}$ & $\begin{array}{c}\text { Pavitation predicted } \\
\text { (\%) }\end{array}$ \\
\hline 8.2 & 61,400 & 1.1 & None & 75,896 & 1.11 & None \\
\hline 8.1 & 32,000 & 0.67 & $10 \%$ of blade & 45,400 & 0.673 & $12 \%$ of the blade \\
\hline 7.5 & 23,000 & 0.63 & $15 \%$ of blade & 36,316 & 0.636 & $18 \%$ of the blade \\
\hline 7.2 & 21,000 & 0.64 & $15 \%$ of blade & 34,000 & 0.649 & $18 \%$ to $24 \%$ of the blade \\
\hline
\end{tabular}

AeroDyn predicted between $2 \%$ and $9 \%$ more cavitation to occur on the blade than observed in the experiments, but in general was in good agreement. The difference between the amount of cavitation predicted with AeroDyn and observed experimentally is attributed to the airfoil minimum pressure coefficients that were obtained using XFOIL.

Guo et al. (Guo, Zhou, and Wang 2015) modeled the same Bahaj et al. turbine using computational fluid dynamics and predicted a critical cavitation number at the blade tip of 1.35 
with $\mathrm{P}_{\mathrm{atm}}=101,325 \mathrm{~Pa}$, a flow speed of $1.4 \mathrm{~m} / \mathrm{s}$, and TSR $=8.7$. AeroDyn predicted a critical cavitation number at the blade tip of 1.32 under the same conditions, increasing the confidence in this model.

\subsection{NACA 63 8xx - Cavitation Prediction}

The 800-mm-diameter turbine modeled in Section 3.1 was simulated with an atmospheric pressure above the free surface of $\mathrm{P}_{\mathrm{atm}}=102,325 \mathrm{~Pa}$ and a midhub depth of $0.6 \mathrm{~m}$, to observe the likelihood of cavitation at normal operating conditions (not in the pressurized tunnel). Note that there was no available experimental data to compare this simulation to. The flow speed was fixed at $1.73 \mathrm{~m} / \mathrm{s}$ and the rotational speeds were varied to cover a range of TSRs. Figure 3 shows the critical and local cavitation numbers for the outer half of the blade toward the tip (radial locations from $\mathrm{r}=0.24 \mathrm{~m}$ to $\mathrm{r}=0.4 \mathrm{~m}$ at the tip), and Figure 4 shows the ratio of these cavitation numbers, with a ratio greater than one indicating the occurrence of cavitation. The markers in Figure 3 represent the critical cavitation numbers at each blade node, and the lines represent the local cavitation number for those nodes, hence cavitation occurs when the lines exceed the markers. 


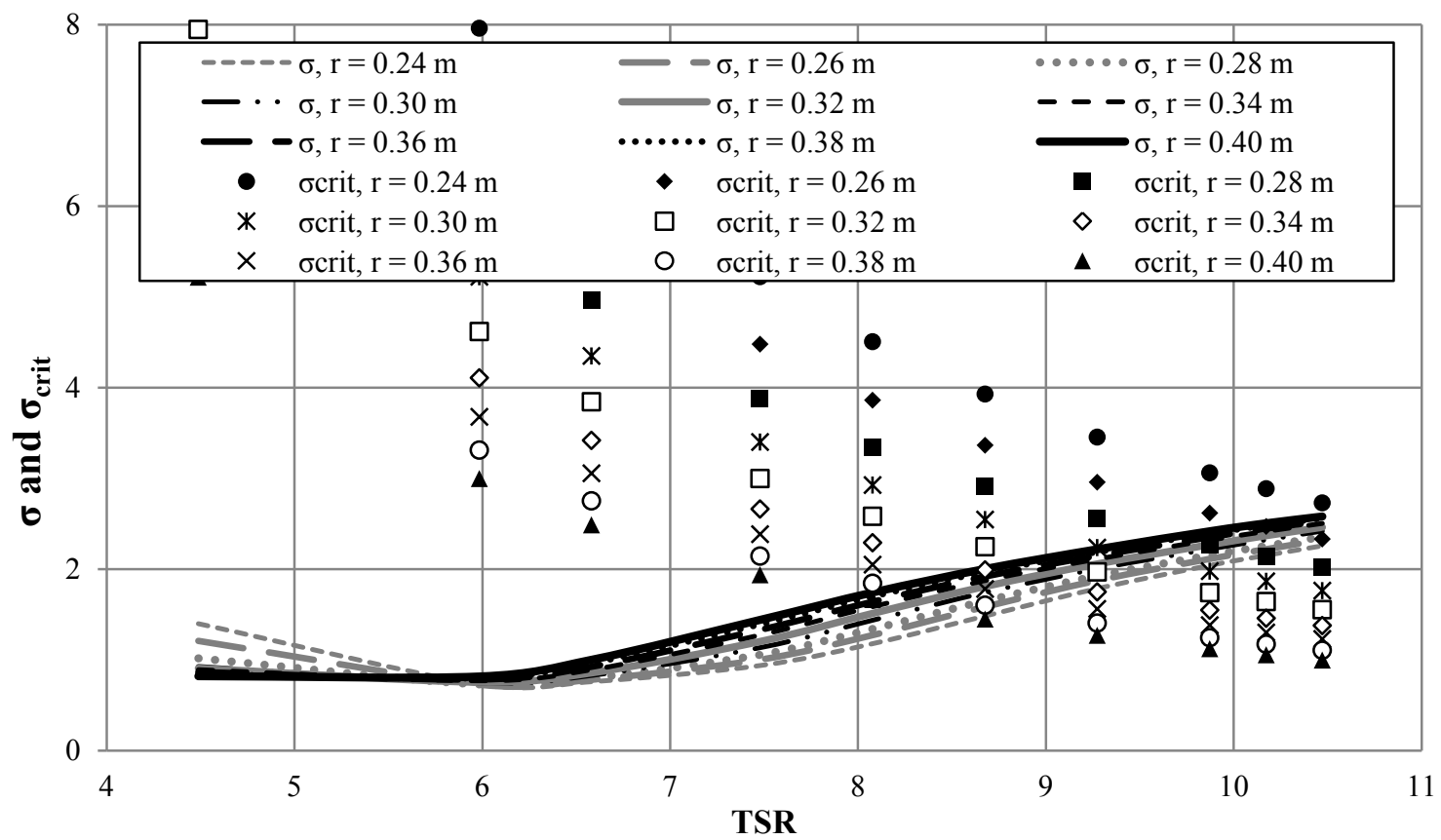

Figure 3. Critical cavitation numbers (markers) and local cavitation numbers (lines) for the 800 mm-diameter MHK turbine

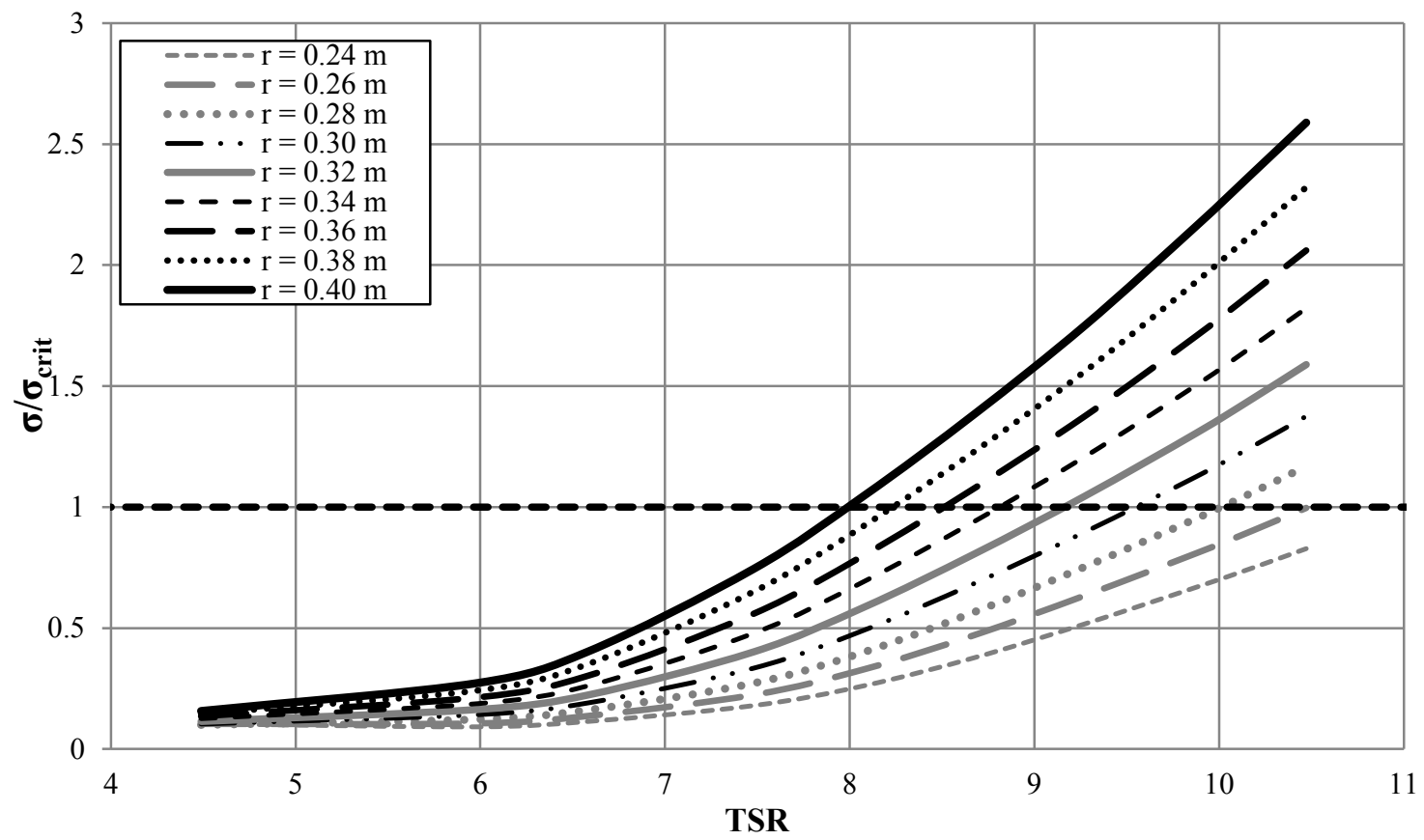

Figure 4. Ratio of local cavitation number to critical cavitation number for the 800 -mm-diameter MHK turbine 
Cavitation was predicted to begin at the blade tip $(\mathrm{r}=0.40 \mathrm{~m})$ at a TSR of 8 . As the TSR increased beyond 8 , the amount of the blade with cavitation increased as well, with up to $35 \%$ of the blade cavitating at a TSR of 10.3. This result suggests that for a large percent of the turbine operating conditions, cavitation will not occur. For realistic turbine operation, control systems can be implemented to maintain the TSR below 8 and avoid cavitation inception. 


\section{Conclusions and Future Work}

AeroDyn V15.04 predicted the performance of two MHK turbines well based on comparison to experimental data. AeroDyn also provided reasonable predictions of cavitation inception based on observations of an 800-mm MHK turbine tested in a cavitation tunnel. This validation provides confidence in the program, which will increase its use as a design tool for predicting turbine performance and cavitation inception on MHK turbines. Future work will build on the development of AeroDyn for MHK by developing added mass algorithms in NREL's FAST framework. This design tool capability will enable MHK turbines to be modeled in FAST with both added mass considerations as well as cavitation predictions. 


\section{References}

Bahaj, A. S., W. M. J. Batten, and G. McCann. 2007. "Experimental verifications of numerical predictions for the hydrodynamic performance of horizontal axis marine current turbines." Renewable Energy no. 32 (15):2479-2490. doi: 10.1016/j.renene.2007.10.001.

Bahaj, A. S., A. F. Molland, J. R. Chaplin, and W. M. J. Batten. 2007. "Power and thrust measurements of marine current turbines under various hydrodynamic flow conditions in a cavitation tunnel and a towing tank." Renewable Energy no. 32 (3):407-426. doi: 10.1016/j.renene.2006.01.012.

Barber, Ramona B., and Michael R. Motley. 2016. "Cavitating response of passively controlled tidal turbines." Journal of Fluids and Structures no. 66:462-475. doi: 10.1016/j.jfluidstructs.2016.08.006.

Batten, W. M. J., A. S. Bahaj, A. F. Molland, and J. R. Chaplin. 2007. "Experimentally validated numerical method for the hydrodynamic design of horizontal axis tidal turbines." Ocean Engineering no. 34 (7):1013-1020. doi: 10.1016/j.oceaneng.2006.04.008.

Batten, W. M. J., A. S. Bahaj, A. F. Molland, and J. R. Chaplin. 2008. "The prediction of the hydrodynamic performance of marine current turbines." Renewable Energy no. 33 (5):1085-1096. doi: 10.1016/j.renene.2007.05.043.

Buckland, H. C., I. Masters, J. A. Orme, and T. Baker. 2013. "Cavitation inception and simulation in blade element momentum theory for modelling tidal stream turbines." Proceedings of the Institution of Mechanical Engineers, Part A: Journal of Power and Energy no. 227 (4):479-485. doi: 10.1177/0957650913477093.

Burton, Tony, David Sharpe, Nick Jenkins, and Ervin Bossanyi. 2001. Wind Energy Handbook. The Atrium, Southern Gate, Chichester, West Sussex PO 19 8SQ, England: John Wiley \& Sons, Ltd.

Clarke, J.A., G. Connor, A.D. Grant, C. Johnstone, and D. MacKenzie. 2007. Development of a contra-rotating tidal current turbine and analysis of performance. In EWTEC. Southampton, UK.

Doman, Darrel A., Robynne E. Murray, Michael J. Pegg, Katie Gracie, Cameron M. Johnstone, and Thomas Nevalainen. 2015. "Tow-tank testing of a 1/20th scale horizontal axis tidal turbine with uncertainty analysis." International Journal of Marine Energy no. 11:105119. doi: 10.1016/j.ijome.2015.06.003.

Drela, Mark. 2001. XFOIL 6.94 User Guide.

Galloway, Pascal W., Luke E. Myers, and AbuBakr S. Bahaj. 2011. Experimental and numerical results of rotor power and thrust of a tidal turbine operating at yaw and in waves. Paper read at WREC, at Sweden

Germain, G., A.S. Bahaj, C.Huxley-Reynard, and P.Roberts. 2007. Facilities for marine current energy converter characterization. Paper read at 7th EWTEC, at Portugal.

Glauert, H. 1935. Airplane propellers, Aerodynamic Theory: Springer Berlin Heidelberg.

Gracie, K., T.M. Nevalainen, C.M. Johnstone, R.E. Murray, D.A. Doman, and M.J. Pegg. 2015. Development of a blade design methodology for overspeed power-regulated tidal turbines. Paper read at EWTEC, at Nantes, France.

Guo, Q., L. J. Zhou, and Z. W. Wang. 2015. "Numerical simulation of cavitation for a horizontal axis marine current turbine." IOP Conference Series: Materials Science and Engineering no. 72 (4):042045. doi: 10.1088/1757-899x/72/4/042045.

Hansen, Martin O. L. 2008. Aerodynamics of Wind Turbines. Second ed. UK and USA: Earthscan. 
Hayman, Greg, Bonnie Jonkman, and Robynne Murray. 2017. NWTC Information Portal (AeroDyn) 2017 [cited 04-May 2017]. Available from https://nwtc.nrel.gov/AeroDyn.

Jason M. Jonkman, Marshall L. Buhl Jr. 2005. FAST User's Guide. In Technical Report NREL/EL-500-38230.

Jonkman, J.M., G.J. Hayman, B.J. Jonkman, and R.R. Damiani. 2016. AeroDyn v15 User's Guide and Theory Manual. National Renewable Energy Laboratory.

Milne, Ian Angus. 2014. An Experimental Investigation of Turbulence and Unsteady Loading on Tidal Turbines. PhD, The University of Auckland.

Molland, A F, A S Bahaj, J R Chaplin, and W M J Batten. 2004. "Measurements and predictions of forces, pressures and cavitation on 2-D sections suitable for marine current turbines." Proceedings of the Institution of Mechanical Engineers, Part M: Journal of Engineering for the Maritime Environment no. 218 (2):127-138.

Murray, Robynne E. 2016. Passively adaptive tidal turbine blades: Design methodology and experimental testing, Mechanical Engineering, Dalhousie University.

Murray, Robynne E., Thomas Nevalainen, Katie Gracie-Orr, Darrel A. Doman, Michael J. Pegg, and Cameron M. Johnstone. 2016. "Passively adaptive tidal turbine blades: Design tool development and initial verification." International Journal of Marine Energy no. 14:101-124.

Neary, Vincent S., Mirko Previsic, Richard A. Jepsen, Michael J. Lawson, Yi-Hsiang Yu, Andrea E. Copping, Arnold A. Fontaine, Kathleen C. Hallett, and Dianne K. Murray. 2014. Methodology for Design and Economic Analysis of Marine Energy Conversion (MEC) Technologies. In Sandia Report SAND2014-9040.

Nevalainen, Thomas, Cameron Johnstone, and Andrew Grant. 2015. Characterising Unsteady Eccentric Loads on Tidal Stream Turbines Using a Dynamic Blade Element Momentum Theory. Paper read at EWTEC, at Nantes, France.

Ning, S.A. 2013. AirfoilPrep Documentation Release 0.1.0. National Renewable Energy Laboratory.

Togneri, M., I. Masters, R. Malki, and A. Rio. 2015. "Flume measurements of lift and drag for selected tidal turbine blade sections." Under review. 


\section{Appendix A}

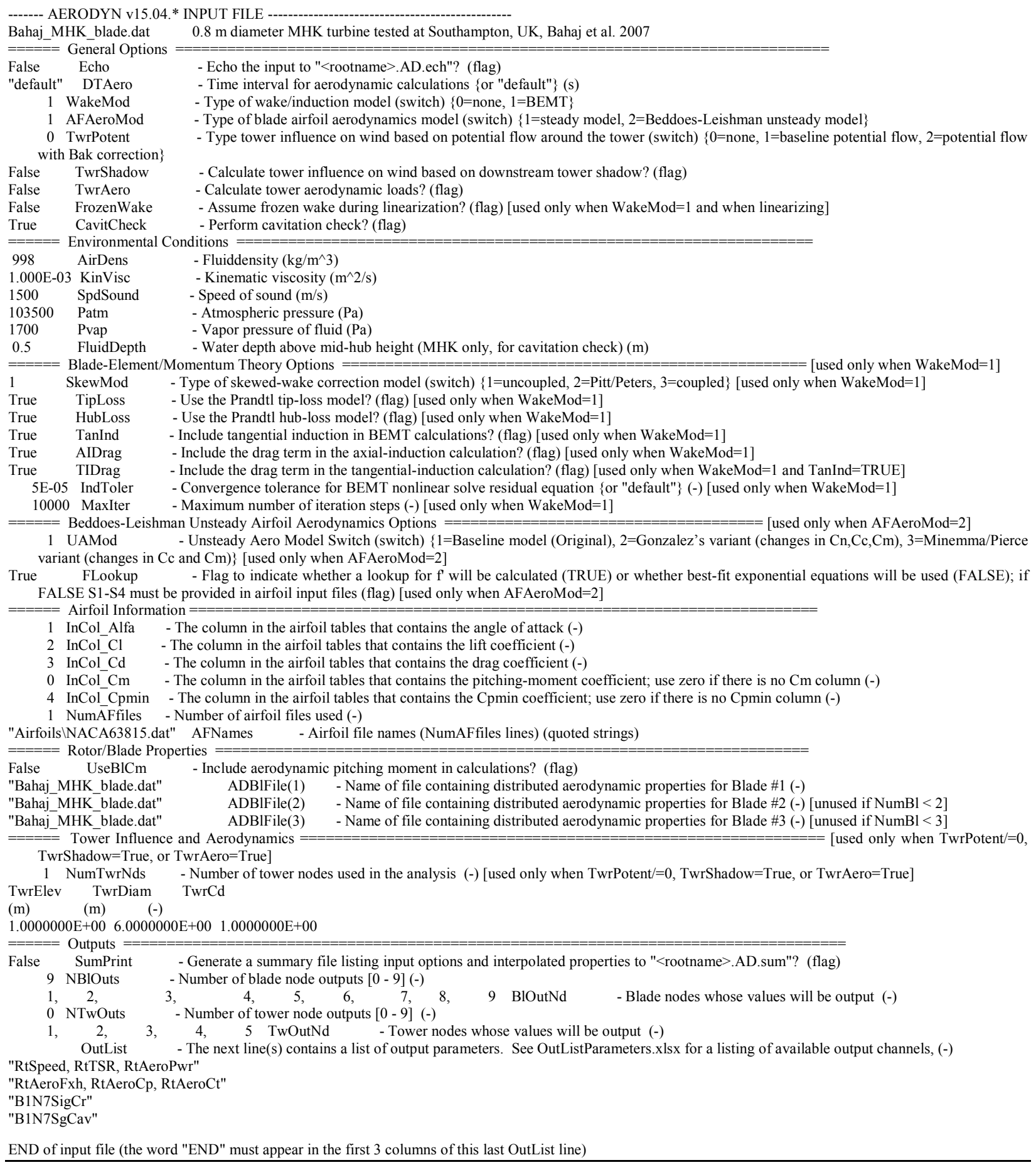

Figure A1. Primary AeroDyn input file 


\section{Appendix B}

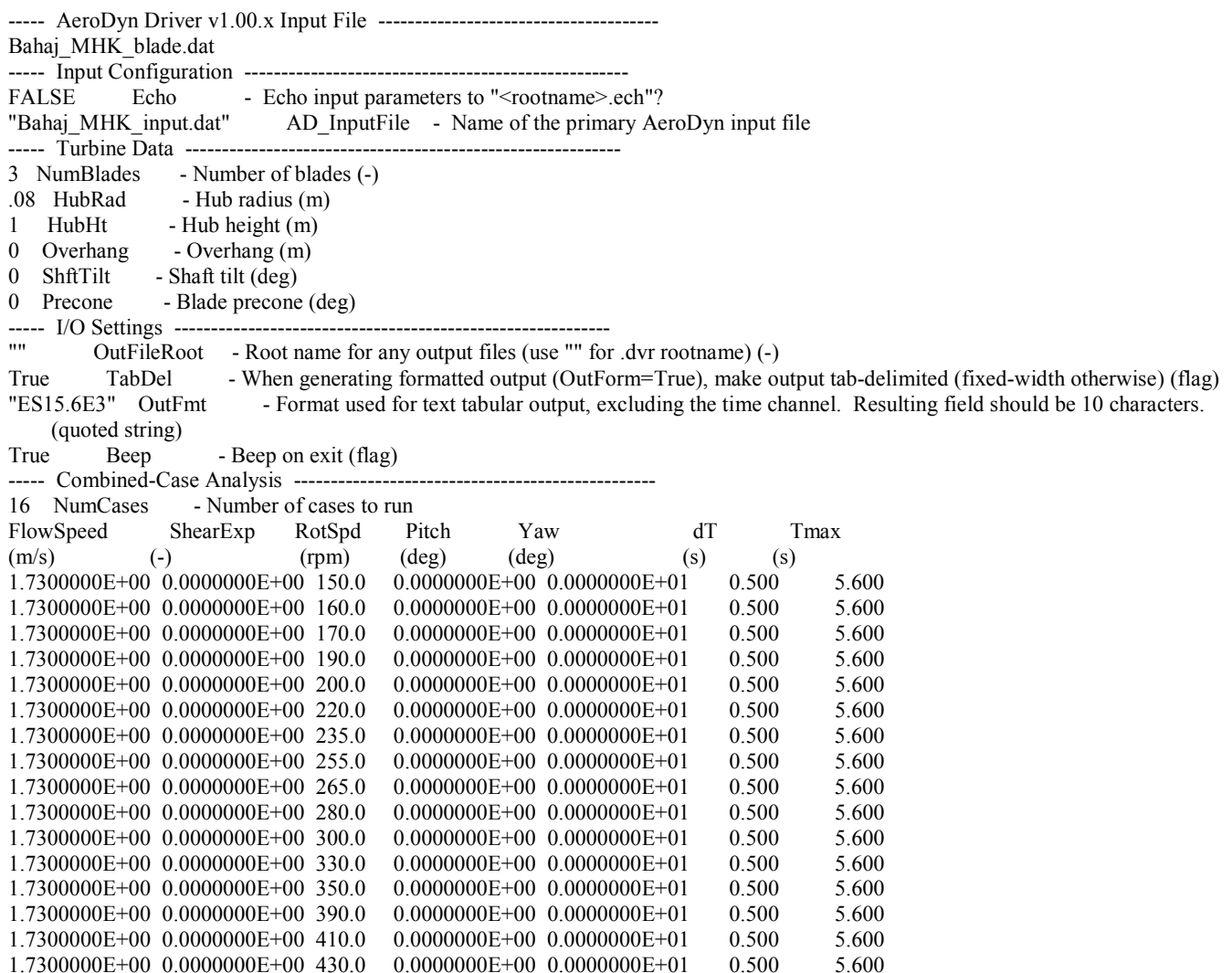

Figure B1. AeroDyn driver file 


\section{Appendix C}

------ AERODYN v15.00.* BLADE DEFINITION INPUT FILE

Bahaj blade tested at Southhampton - blade input properties

\begin{tabular}{|c|c|c|c|c|c|c|}
\hline \multirow{2}{*}{$\begin{array}{l}\quad 17 \\
\text { B1Spn } \\
(\mathrm{m})\end{array}$} & \multirow{2}{*}{$\begin{array}{l}\text { NumBINds } \\
\text { BlCrvAC } \\
\text { (m) }\end{array}$} & \multicolumn{5}{|c|}{ - Number of blade nodes used in the analysis (-) } \\
\hline & & $\begin{array}{l}\text { B1SwpAC } \\
\text { (m) }\end{array}$ & $\begin{array}{l}\text { BlCrvAng } \\
\text { (deg) }\end{array}$ & $\begin{array}{l}\text { BlTwist } \\
\text { (deg) }\end{array}$ & $\begin{array}{l}\text { BlChord } \\
\text { (m) }\end{array}$ & $\begin{array}{l}\text { BlAFID } \\
(-)\end{array}$ \\
\hline $0.00 \mathrm{E}+00$ & $0.00 \mathrm{E}+00$ & $0.00 \mathrm{E}+00$ & $0.00 \mathrm{E}+00$ & $2.00 \mathrm{E}+01$ & $5.00 \mathrm{E}-02$ & $1.00 \mathrm{E}+00$ \\
\hline $2.00 \mathrm{E}-02$ & $0.00 \mathrm{E}+00$ & $0.00 \mathrm{E}+00$ & $0.00 \mathrm{E}+00$ & $1.73 \mathrm{E}+01$ & $4.81 \mathrm{E}-02$ & $1.00 \mathrm{E}+00$ \\
\hline $4.00 \mathrm{E}-02$ & $0.00 \mathrm{E}+00$ & $0.00 \mathrm{E}+00$ & $0.00 \mathrm{E}+00$ & $1.45 \mathrm{E}+01$ & $4.62 \mathrm{E}-02$ & $1.00 \mathrm{E}+00$ \\
\hline $6.00 \mathrm{E}-02$ & $0.00 \mathrm{E}+00$ & $0.00 \mathrm{E}+00$ & $0.00 \mathrm{E}+00$ & $1.28 \mathrm{E}+01$ & $4.44 \mathrm{E}-02$ & $1.00 \mathrm{E}+00$ \\
\hline 8.00E-02 & $0.00 \mathrm{E}+00$ & $0.00 \mathrm{E}+00$ & $0.00 \mathrm{E}+00$ & $1.11 \mathrm{E}+01$ & $4.25 \mathrm{E}-02$ & $1.00 \mathrm{E}+00$ \\
\hline $1.00 \mathrm{E}-01$ & $0.00 \mathrm{E}+00$ & $0.00 \mathrm{E}+00$ & $0.00 \mathrm{E}+00$ & $1.00 \mathrm{E}+01$ & $4.07 \mathrm{E}-02$ & $1.00 \mathrm{E}+00$ \\
\hline $1.20 \mathrm{E}-01$ & $0.00 \mathrm{E}+00$ & $0.00 \mathrm{E}+00$ & $0.00 \mathrm{E}+00$ & $8.90 \mathrm{E}+00$ & $3.88 \mathrm{E}-02$ & $1.00 \mathrm{E}+00$ \\
\hline $1.40 \mathrm{E}-01$ & $0.00 \mathrm{E}+00$ & $0.00 \mathrm{E}+00$ & $0.00 \mathrm{E}+00$ & $8.15 \mathrm{E}+00$ & $3.69 \mathrm{E}-02$ & $1.00 \mathrm{E}+00$ \\
\hline $1.60 \mathrm{E}-01$ & $0.00 \mathrm{E}+00$ & $0.00 \mathrm{E}+00$ & $0.00 \mathrm{E}+00$ & $7.40 \mathrm{E}+00$ & $3.50 \mathrm{E}-02$ & $1.00 \mathrm{E}+00$ \\
\hline $1.80 \mathrm{E}-01$ & $0.00 \mathrm{E}+00$ & $0.00 \mathrm{E}+00$ & $0.00 \mathrm{E}+00$ & $6.95 \mathrm{E}+00$ & $3.31 \mathrm{E}-02$ & $1.00 \mathrm{E}+00$ \\
\hline $2.00 \mathrm{E}-01$ & $0.00 \mathrm{E}+00$ & $0.00 \mathrm{E}+00$ & $0.00 \mathrm{E}+00$ & $6.50 \mathrm{E}+00$ & $3.12 \mathrm{E}-02$ & $1.00 \mathrm{E}+00$ \\
\hline $2.20 \mathrm{E}-01$ & $0.00 \mathrm{E}+00$ & $0.00 \mathrm{E}+00$ & $0.00 \mathrm{E}+00$ & $6.20 \mathrm{E}+00$ & $2.94 \mathrm{E}-02$ & $1.00 \mathrm{E}+00$ \\
\hline $2.40 \mathrm{E}-01$ & $0.00 \mathrm{E}+00$ & $0.00 \mathrm{E}+00$ & $0.00 \mathrm{E}+00$ & $5.90 \mathrm{E}+00$ & $2.75 \mathrm{E}-02$ & $1.00 \mathrm{E}+00$ \\
\hline $2.60 \mathrm{E}-01$ & $0.00 \mathrm{E}+00$ & $0.00 \mathrm{E}+00$ & $0.00 \mathrm{E}+00$ & $5.65 \mathrm{E}+00$ & $2.57 \mathrm{E}-02$ & $1.00 \mathrm{E}+00$ \\
\hline $2.80 \mathrm{E}-01$ & $0.00 \mathrm{E}+00$ & $0.00 \mathrm{E}+00$ & $0.00 \mathrm{E}+00$ & $5.40 \mathrm{E}+00$ & $2.38 \mathrm{E}-02$ & $1.00 \mathrm{E}+00$ \\
\hline $3.00 \mathrm{E}-01$ & $0.00 \mathrm{E}+00$ & $0.00 \mathrm{E}+00$ & $0.00 \mathrm{E}+00$ & $5.20 \mathrm{E}+00$ & 2.19E-02 & $1.00 \mathrm{E}+00$ \\
\hline $3.20 \mathrm{E}-01$ & $0.00 \mathrm{E}+00$ & $0.00 \mathrm{E}+00$ & $0.00 \mathrm{E}+00$ & $5.00 \mathrm{E}+00$ & $2.00 \mathrm{E}-02$ & $1.00 \mathrm{E}+00$ \\
\hline
\end{tabular}

Figure C1. AeroDyn blade input file 


\section{Appendix D}

! ---------- AirfoilInfo v1.01.x Input File -

! NACA63815 from HarpOpt data to -180 to $180 \mathrm{deg} \mathrm{Cl}, \mathrm{Cd}$, (no $\mathrm{Cm}$ ) versus AOA data

! note that this file uses Marshall Buhl's new input file processing; start all comment lines with !

DEFAULT InterpOrd ! Interpolation order to use for quasi-steady table lookup $\{1=$ linear; $3=$ cubic spline; "default" $\}$ [default=3]

1 NonDimArea ! The non-dimensional area of the airfoil ( $\left.\operatorname{area} / \mathrm{chord}^{\wedge} 2\right)($ set to 1.0 if unsure or unneeded)

0 NumCoords ! The number of coordinates in the airfoil shape file. Set to zero if coordinates not included.

!......... $\mathrm{x}-\mathrm{y}$ coordinates are next if NumCoords $>0$.............

1 NumTabs ! Number of airfoil tables in this file. Each table must have lines for Re and Ctrl.

! data for table 1

! -

0.5 Re ! Reynolds number in millions

0 Ctrl ! Control setting (must be 0 for current Airfoillnfo)

True InclUAdata ! Is unsteady aerodynamics data included in this table? If TRUE, then include 30 UA coefficients below this line

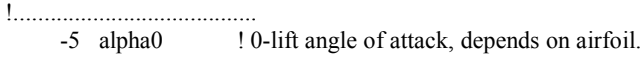

20 alpha1 ! Angle of attack at $\mathrm{f}=0.7$, (approximately the stall angle) for AOA $>$ alpha0. (deg)

-160 alpha 2 ! Angle of attack at $\mathrm{f}=0.7$, (approximately the stall angle) for $\mathrm{AOA}<\mathrm{alpha}$. ( $\mathrm{deg}$ )

1 eta_e ! Recovery factor in the range $[0.85-0.95]$ used only for UAMOD $=1$, it is set to 1 in the code when flookup=True. (-)

6.0031 C_nalpha ! Slope of the $2 \mathrm{D}$ normal force coefficient curve. $(1 / \mathrm{rad})$

Default T_fo ! Initial value of the time constant associated with Df in the expression of Df and $\mathrm{f}^{\prime \prime}$. [default $=3$ ]

Default T_V0 ! Initial value of the time constant associated with the vortex lift decay process; it is used in the expression of Cvn. It depends on Re,M, and airfoil class. [default $=6$ ]

Default T_p ! Boundary-layer,leading edge pressure gradient time constant in the expression of Dp. It should be tuned based on airfoil experimental data. $[$ default $=1.7]$

Default T_VL ! Initial value of the time constant associated with the vortex advection process; it represents the non-dimensional time in semi-chords, needed for a vortex to travel from LE to trailing edge (TE); it is used in the expression of Cvn. It depends on Re, M (weakly), and airfoil. [valid range $=6$ - 13, default $=11]$

Default b1 ! Constant in the expression of phi alpha^ ${ }^{\wedge}$ and phi $\mathrm{q}^{\wedge} \mathrm{c}$. This value is relatively insensitive for thin airfoils, but may be different for turbine airfoils. [from experimental results, defaults to 0.14 ]

Default b2 ! Constant in the expression of phi_alpha^c and phi_q^ $\mathrm{q}^{\wedge}$. This value is relatively insensitive for thin airfoils, but may be different for turbine airfoils. [from experimental results, defaults to 0.53 ]

Default b5 ! Constant in the expression of $\mathrm{K}^{\prime \prime \prime} \_\mathrm{q}, \mathrm{Cm} \_\mathrm{q} \wedge \mathrm{nc}$, and k_m,q. [from experimental results, defaults to 5]

Default A1 ! Constant in the expression of phi_alpha^ $\mathrm{c}$ and $\mathrm{phi}_{-} \mathrm{q}^{\wedge} \mathrm{c}$. This value is relatively insensitive for thin airfoils, but may be different for turbine airfoils. [from experimental results, defaults to 0.3 ]

Default A2 ! Constant in the expression of phi_alpha^ ${ }^{\wedge}$ and phi_q $q^{\wedge} \mathrm{c}$. This value is relatively insensitive for thin airfoils, but may be different for turbine airfoils. [from experimental results, defaults to 0.7]

Default A5 ! Constant in the expression of $\mathrm{K}^{\prime \prime \prime}$ q, $\mathrm{Cm} \_\mathrm{q}^{\wedge} \mathrm{nc}$, and k_m,q. [from experimental results, defaults to 1]

1 S1 ! Constant in the f curve best-fit for alpha0 $<=\mathrm{AOA}<=$ alpha 1; by definition it depends on the airfoil. [ignored if UAMod $<>1$ ]

1 S2 ! Constant in the f curve best-fit for AOA $>$ alpha1; by definition it depends on the airfoil. [ignored if UAMod $<>1$ ]

1 S3 ! Constant in the f curve best-fit for alpha $2<=\mathrm{AOA}<\mathrm{alpha} 0$; by definition it depends on the airfoil. [ignored if $\mathrm{UAM}$ od $<>1$ ]

1 S4 ! Constant in the f curve best-fit for $\quad$ AOA $<$ alpha2; by definition it depends on the airfoil. [ignored if UAMod $<>1$ ]

$0 \mathrm{Cn} 1 \quad$ ! Critical value of $\mathrm{C} 0 \mathrm{n}$ at leading edge separation. It should be extracted from airfoil data at a given Mach and Reynolds number. It can be calculated from the static value of $\mathrm{Cn}$ at either the break in the pitching moment or the loss of chord force at the onset of stall. It is close to the condition of maximum lift of the airfoil at low Mach numbers.

! As Cn1 for negative AOAs.

0.19 St_sh ! Strouhal's shedding frequency constant. [default $=0.19$ ]

$.01 \quad \mathrm{Cd} 0 \quad$ !2D drag coefficient value at 0 -lift.

$0 \mathrm{Cm} 0 \quad$ ! 2D pitching moment coefficient about $1 / 4$-chord location, at 0 -lift, positive if nose up. [If the aerodynamics coefficients table does not include a column for $\mathrm{Cm}$, this needs to be set to 0.0$]$

$0 \mathrm{k} 0$ ! Constant in the $\operatorname{lhat}(\mathrm{x})$ cp curve best-fit; $=\left(\right.$ hat $\left.(\mathrm{x}) \_\mathrm{AC}-0.25\right)$. [ignored if UAMod $<>1$ ]

$0 \mathrm{k} 1 \quad$ ! Constant in the hat $(\mathrm{x})$ cep curve best-fit. [ignored if UAMod $<>1$ ]

$0 \quad \mathrm{k} 2 \quad$ ! Constant in the $\operatorname{lhat}(\mathrm{x})$ cp curve best-fit. [ignored if UAMod $<>1$ ]

$0 \mathrm{k} 3$ ! Constant in the $\operatorname{lhat}(\mathrm{x}) \_\mathrm{cp}$ curve best-fit. [ignored if UAMod $<>1$ ]

$0 \mathrm{k} 1$ hat $\quad$ ! Constant in the expression of Cc due to leading edge vortex effects. [ignored if UAMod $<>1$ ]

Default $\quad \mathrm{x}$ cp bar $\quad$ ! Constant in the expression of $\backslash$ hat $(\mathrm{x}) \mathrm{cp}^{\wedge} \mathrm{v}$. [ignored if UAMod $<>1$, default $=0.2$ ]

Default UACutout ! Angle of attack above which unsteady aerodynamics are disabled (deg). [Specifying the string "Default" sets UACutout to 45 degrees]

10 filtCutOff ! Cut-off frequency ( $-3 \mathrm{~dB}$ corner frequency) for low-pass filtering the AoA input to UA, as well as the 1 st and 2 nd derivatives (Hz) [default $=20$

! Table of aerodynamics coefficients

68 NumAlf ! Number of data lines in the following table

! Alpha

! (deg)

$-1.80 \mathrm{E}+02$

$-1.70 \mathrm{E}+02$

$-1.60 \mathrm{E}+02$

$-1.50 \mathrm{E}+02$

$-1.40 \mathrm{E}+02$

$-1.30 \mathrm{E}+02$

$-1.20 \mathrm{E}+02$

$-1.10 \mathrm{E}+02$

$-1.00 \mathrm{E}+02$

$-9.00 \mathrm{E}+01$

(-)

$0.00 \mathrm{E}+00$

5.81E-01

$8.94 \mathrm{E}-01$

7.32E-01

6.43E-01

$5.53 \mathrm{E}-01$

4.42E-01

3.07E-01

$1.55 \mathrm{E}-01$

$0.00 \mathrm{E}+00$

$\mathrm{Cd}$

(-)

$1.00 \mathrm{E}-02$

$1.00 \mathrm{E}-02$

$9.04 \mathrm{E}-02$

$2.59 \mathrm{E}-01$

4.65E-01

$6.86 \mathrm{E}-01$

$8.95 \mathrm{E}-01$

$1.07 \mathrm{E}+00$

$1.18 \mathrm{E}+00$

$-8.00 \mathrm{E}+0$

$-1.55 \mathrm{E}-01$

$1.23 \mathrm{E}+00$

$1.18 \mathrm{E}+00$

$\begin{array}{ll}\begin{array}{l}\text { Cm } \\ (-)\end{array} & \begin{array}{l}\text { Cpmin } \\ (-)\end{array} \\ 3.13 \mathrm{E}-01 & -1.40 \mathrm{E}+00 \\ 3.43 \mathrm{E}-01 & -1.60 \mathrm{E}+00 \\ 3.65 \mathrm{E}-01 & -1.80 \mathrm{E}+00 \\ 3.82 \mathrm{E}-01 & -2.00 \mathrm{E}+00 \\ 3.94 \mathrm{E}-01 & -2.50 \mathrm{E}+00 \\ 4.01 \mathrm{E}-01 & -3.00 \mathrm{E}+00 \\ 4.04 \mathrm{E}-01 & -3.50 \mathrm{E}+00 \\ 4.05 \mathrm{E}-01 & -4.00 \mathrm{E}+00 \\ 4.03 \mathrm{E}-01 & -5.00 \mathrm{E}+00 \\ 3.98 \mathrm{E}-01 & -5.50 \mathrm{E}+00 \\ 3.92 \mathrm{E}-01 & -6.30 \mathrm{E}+00\end{array}$




\begin{tabular}{|c|c|c|c|c|}
\hline$-7.00 \mathrm{E}+01$ & $-3.07 \mathrm{E}-01$ & $1.07 \mathrm{E}+00$ & $3.84 \mathrm{E}-01$ & $-6.30 \mathrm{E}+00$ \\
\hline$-6.00 \mathrm{E}+01$ & $-4.42 \mathrm{E}-01$ & $8.95 \mathrm{E}-01$ & $3.74 \mathrm{E}-01$ & $-6.30 \mathrm{E}+00$ \\
\hline$-5.00 \mathrm{E}+01$ & $-5.53 \mathrm{E}-01$ & $6.86 \mathrm{E}-01$ & $3.64 \mathrm{E}-01$ & $-6.30 \mathrm{E}+00$ \\
\hline$-4.00 \mathrm{E}+01$ & $-6.43 \mathrm{E}-01$ & $4.65 \mathrm{E}-01$ & $3.52 \mathrm{E}-01$ & $-6.30 \mathrm{E}+00$ \\
\hline$-3.00 \mathrm{E}+01$ & $-7.32 \mathrm{E}-01$ & $2.59 \mathrm{E}-01$ & $3.39 \mathrm{E}-01$ & $-6.30 E+00$ \\
\hline$-2.00 \mathrm{E}+01$ & $-8.94 \mathrm{E}-01$ & $9.04 \mathrm{E}-02$ & $3.25 \mathrm{E}-01$ & $-6.00 \mathrm{E}+00$ \\
\hline$-1.00 \mathrm{E}+01$ & $-4.54 \mathrm{E}-01$ & $1.45 \mathrm{E}-02$ & $3.10 \mathrm{E}-01$ & $-4.50 \mathrm{E}+00$ \\
\hline$-6.00 E+00$ & $-1.98 \mathrm{E}-02$ & $1.15 \mathrm{E}-02$ & $2.94 \mathrm{E}-01$ & $-2.90 \mathrm{E}+00$ \\
\hline$-5.50 \mathrm{E}+00$ & $3.45 \mathrm{E}-02$ & $1.07 \mathrm{E}-02$ & $2.77 \mathrm{E}-01$ & $-2.80 \mathrm{E}+00$ \\
\hline$-5.00 \mathrm{E}+00$ & $8.88 \mathrm{E}-02$ & $9.98 \mathrm{E}-03$ & $2.60 \mathrm{E}-01$ & $-2.63 E+00$ \\
\hline$-4.50 \mathrm{E}+00$ & $1.48 \mathrm{E}-01$ & $9.97 \mathrm{E}-03$ & $2.41 \mathrm{E}-01$ & $-2.29 \mathrm{E}+00$ \\
\hline$-4.00 \mathrm{E}+00$ & $2.06 \mathrm{E}-01$ & $9.96 \mathrm{E}-03$ & $2.21 \mathrm{E}-01$ & $-1.95 \mathrm{E}+00$ \\
\hline$-2.00 \mathrm{E}+00$ & $4.60 \mathrm{E}-01$ & $9.41 \mathrm{E}-03$ & $2.01 \mathrm{E}-01$ & $-8.75 \mathrm{E}-01$ \\
\hline$-1.50 \mathrm{E}+00$ & $5.68 \mathrm{E}-01$ & $9.41 \mathrm{E}-03$ & $1.79 \mathrm{E}-01$ & $-7.81 \mathrm{E}-01$ \\
\hline $1.00 \mathrm{E}+00$ & $8.12 \mathrm{E}-01$ & $8.36 \mathrm{E}-03$ & $1.56 \mathrm{E}-01$ & $-8.13 \mathrm{E}-01$ \\
\hline $1.50 \mathrm{E}+00$ & $8.67 \mathrm{E}-01$ & $8.34 \mathrm{E}-03$ & $1.16 \mathrm{E}-01$ & $-8.56 \mathrm{E}-01$ \\
\hline $2.00 \mathrm{E}+00$ & $9.21 \mathrm{E}-01$ & 8.33E-03 & $1.04 \mathrm{E}-01$ & $-9.00 \mathrm{E}-01$ \\
\hline $2.80 \mathrm{E}+00$ & $1.05 \mathrm{E}+00$ & $8.80 \mathrm{E}-03$ & $9.16 \mathrm{E}-02$ & $-9.81 \mathrm{E}-01$ \\
\hline $4.00 \mathrm{E}+00$ & $1.14 \mathrm{E}+00$ & $9.27 \mathrm{E}-03$ & $7.85 \mathrm{E}-02$ & $-1.40 \mathrm{E}+00$ \\
\hline $5.80 \mathrm{E}+00$ & $1.30 \mathrm{E}+00$ & $1.42 \mathrm{E}-02$ & $6.49 \mathrm{E}-02$ & $-1.70 \mathrm{E}+00$ \\
\hline $7.00 \mathrm{E}+00$ & $1.38 \mathrm{E}+00$ & $1.61 \mathrm{E}-02$ & $5.08 \mathrm{E}-02$ & $-3.25 E+00$ \\
\hline $7.50 \mathrm{E}+00$ & $1.40 \mathrm{E}+00$ & $1.73 \mathrm{E}-02$ & $3.64 \mathrm{E}-02$ & $-2.30 \mathrm{E}+00$ \\
\hline $8.00 \mathrm{E}+00$ & $1.43 \mathrm{E}+00$ & $1.85 \mathrm{E}-02$ & $2.18 \mathrm{E}-02$ & $-2.40 \mathrm{E}+00$ \\
\hline $9.00 \mathrm{E}+00$ & $1.49 \mathrm{E}+00$ & $2.05 \mathrm{E}-02$ & $1.29 \mathrm{E}-02$ & $-2.50 \mathrm{E}+00$ \\
\hline $9.50 \mathrm{E}+00$ & $1.51 \mathrm{E}+00$ & $2.22 \mathrm{E}-02$ & $-2.80 \mathrm{E}-03$ & $-2.70 \mathrm{E}+00$ \\
\hline $1.00 \mathrm{E}+01$ & $1.54 \mathrm{E}+00$ & $2.39 \mathrm{E}-02$ & $-2.51 \mathrm{E}-02$ & $-2.80 \mathrm{E}+00$ \\
\hline $1.05 \mathrm{E}+01$ & $1.56 \mathrm{E}+00$ & $2.64 \mathrm{E}-02$ & $-4.19 \mathrm{E}-02$ & $-2.90 \mathrm{E}+00$ \\
\hline $1.10 \mathrm{E}+01$ & $1.59 \mathrm{E}+00$ & $2.88 \mathrm{E}-02$ & $-5.21 \mathrm{E}-02$ & $-2.90 \mathrm{E}+00$ \\
\hline $1.15 \mathrm{E}+01$ & $1.62 \mathrm{E}+00$ & $3.13 \mathrm{E}-02$ & $-6.10 \mathrm{E}-02$ & $-3.30 \mathrm{E}+00$ \\
\hline $1.20 \mathrm{E}+01$ & $1.64 \mathrm{E}+00$ & $3.37 \mathrm{E}-02$ & $-7.07 \mathrm{E}-02$ & $-3.60 \mathrm{E}+00$ \\
\hline $1.25 \mathrm{E}+01$ & $1.66 \mathrm{E}+00$ & $3.72 \mathrm{E}-02$ & $-7.22 \mathrm{E}-02$ & $-4.00 \mathrm{E}+00$ \\
\hline $1.30 \mathrm{E}+01$ & $1.67 \mathrm{E}+00$ & $4.06 \mathrm{E}-02$ & $-7.34 \mathrm{E}-02$ & $-4.10 \mathrm{E}+00$ \\
\hline $1.35 \mathrm{E}+01$ & $1.68 \mathrm{E}+00$ & $4.50 \mathrm{E}-02$ & $-7.72 \mathrm{E}-02$ & $-4.30 \mathrm{E}+00$ \\
\hline $1.40 \mathrm{E}+01$ & $1.69 \mathrm{E}+00$ & $4.94 \mathrm{E}-02$ & $-8.07 \mathrm{E}-02$ & $-4.50 \mathrm{E}+00$ \\
\hline $1.45 \mathrm{E}+01$ & $1.70 \mathrm{E}+00$ & $5.29 \mathrm{E}-02$ & $-8.25 \mathrm{E}-02$ & $-5.00 \mathrm{E}+00$ \\
\hline $1.50 \mathrm{E}+01$ & $1.72 \mathrm{E}+00$ & $5.63 \mathrm{E}-02$ & $-8.41 \mathrm{E}-02$ & $-5.20 \mathrm{E}+00$ \\
\hline $1.55 \mathrm{E}+01$ & $1.72 \mathrm{E}+00$ & $6.30 \mathrm{E}-02$ & $-8.69 \mathrm{E}-02$ & $-5.30 \mathrm{E}+00$ \\
\hline $1.60 \mathrm{E}+01$ & $1.73 \mathrm{E}+00$ & $6.96 \mathrm{E}-02$ & $-9.12 \mathrm{E}-02$ & $-5.40 \mathrm{E}+00$ \\
\hline $1.65 \mathrm{E}+01$ & $1.74 \mathrm{E}+00$ & $7.63 \mathrm{E}-02$ & $-9.46 \mathrm{E}-02$ & $-5.50 \mathrm{E}+00$ \\
\hline $1.70 \mathrm{E}+01$ & $1.74 \mathrm{E}+00$ & $8.29 \mathrm{E}-02$ & $-9.71 E-02$ & $-5.60 \mathrm{E}+00$ \\
\hline $2.00 \mathrm{E}+01$ & $1.72 \mathrm{E}+00$ & $1.28 \mathrm{E}-01$ & $-1.01 \mathrm{E}-01$ & $-6.00 \mathrm{E}+00$ \\
\hline $3.00 \mathrm{E}+01$ & $1.05 \mathrm{E}+00$ & $2.59 \mathrm{E}-01$ & $-1.08 \mathrm{E}-01$ & $-6.30 \mathrm{E}+00$ \\
\hline $4.00 \mathrm{E}+01$ & $9.18 \mathrm{E}-01$ & $4.65 \mathrm{E}-01$ & $-1.13 \mathrm{E}-01$ & $-6.30 \mathrm{E}+00$ \\
\hline $5.00 \mathrm{E}+01$ & 7.91E-01 & $6.86 \mathrm{E}-01$ & $-1.16 \mathrm{E}-01$ & $-6.30 \mathrm{E}+00$ \\
\hline $6.00 \mathrm{E}+01$ & $6.32 \mathrm{E}-01$ & $8.95 \mathrm{E}-01$ & $-1.20 \mathrm{E}-01$ & $-6.30 \mathrm{E}+00$ \\
\hline $7.00 \mathrm{E}+01$ & $4.38 \mathrm{E}-01$ & $1.07 \mathrm{E}+00$ & $-1.24 \mathrm{E}-01$ & $-6.30 \mathrm{E}+00$ \\
\hline $8.00 \mathrm{E}+01$ & $2.21 \mathrm{E}-01$ & $1.18 \mathrm{E}+00$ & $-1.23 \mathrm{E}-01$ & $-6.30 \mathrm{E}+00$ \\
\hline $9.00 \mathrm{E}+01$ & $0.00 \mathrm{E}+00$ & $1.23 \mathrm{E}+00$ & $-1.16 \mathrm{E}-01$ & $-6.30 \mathrm{E}+00$ \\
\hline $1.00 \mathrm{E}+02$ & $-1.55 \mathrm{E}-01$ & $1.18 \mathrm{E}+00$ & $-1.16 \mathrm{E}-01$ & $-5.00 \mathrm{E}+00$ \\
\hline $1.10 \mathrm{E}+02$ & $-3.07 \mathrm{E}-01$ & $1.07 \mathrm{E}+00$ & $-1.16 \mathrm{E}-01$ & $-4.50 \mathrm{E}+00$ \\
\hline $1.20 \mathrm{E}+02$ & $-4.42 \mathrm{E}-01$ & 8.95E-01 & $-1.15 \mathrm{E}-01$ & $-4.00 \mathrm{E}+00$ \\
\hline $1.30 \mathrm{E}+02$ & $-5.53 \mathrm{E}-01$ & $6.86 \mathrm{E}-01$ & $-1.15 \mathrm{E}-01$ & $-3.50 \mathrm{E}+00$ \\
\hline $1.40 \mathrm{E}+02$ & $-6.43 E-01$ & $4.65 \mathrm{E}-01$ & $-1.15 \mathrm{E}-01$ & $-2.80 \mathrm{E}+00$ \\
\hline $1.50 \mathrm{E}+02$ & $-7.32 \mathrm{E}-01$ & $2.59 \mathrm{E}-01$ & $-1.14 \mathrm{E}-01$ & $-2.00 \mathrm{E}+00$ \\
\hline $1.60 \mathrm{E}+02$ & $-8.94 \mathrm{E}-01$ & $9.04 \mathrm{E}-02$ & $-1.15 \mathrm{E}-01$ & $-1.50 \mathrm{E}+00$ \\
\hline $1.70 \mathrm{E}+02$ & $-5.81 \mathrm{E}-01$ & $1.00 \mathrm{E}-02$ & $-1.16 \mathrm{E}-01$ & $-1.00 \mathrm{E}+00$ \\
\hline $1.80 \mathrm{E}+02$ & $0.00 \mathrm{E}+00$ & $1.00 \mathrm{E}-02$ & $3.13 \mathrm{E}-01$ & $-1.40 \mathrm{E}+00$ \\
\hline
\end{tabular}

Figure D1. Airfoil input file 